\title{
IMPEDANCE MEASUREMENTS IN THE DIAGNOSIS OF MENIERE'S DISEASE
}

\author{
LINDA LLOYD, B.A. (Sp. \& H. THERAPY) (WITWATERSRAND) \\ Speech Therapy Department, Groote Schuur Hospital \\ Cape Town
}

\section{SUMMARY}

Meniere's disease is discussed in terms of diagnostic difficulties, histological . findings and treatments pointing to the use of impedance techniques with this condition. Ten subjects were given a questionnaire, regarding the symptoms experienced at the time of testing and impedance measures were conducted. Acoust ic impedance values were higher in $80 \%$ of the affected ears when compared to the unaffected ears. Four of these values were more than double those in the unaffected ears and three were above normal limits. Therefore, increased endolymphatic pressure appears to be reflected in the test results. It is felt that impedance techniques should be.included in the test battery for the diagnosis of Meniere's disease.

\section{OPSOMMING}

Menier e se sindroom word behandel in terme van diagnostiese probleme, histologiese bevindings en behandeling en dui op die gebruik van impedanstegnieke vir hierdie toestand. Aan tien proefpersone is daar 'n vraelys uitgedeel aanga ande die simptome wat ervaar is tydens toetsing en 'n opname van impedansmetings is gemaak. Ako estiese-impedans waardes was hoër in $80 \%$ van die aangetaste ore in vergelyking met die onaangetaste ore. Vier van hierdie waardes was meer as dubbel vergelyk met die van die onaangetaste ore, en drie was hoër as die normale perke. Derhalwe, blyk dit dat verhoogde endolimfatiese druk weerspieël word in hierdie toetsresultate. Die skrywer is van mening dat impedansmeting-tegnieke in die toekoms, moontlik in die toetsbatterei vir diagnose van Meniere se sindroom ingesluit sal word.

The difficulties in diagnosing Meniere's disease have been mentioned throughout the literature, both from the point of view of the audiologist and that of the ear, nose and throat specialist. Little research has apparently been conducted into the possible application of the recently developed im pedance techniques in the diagnosis of this disease. 


\section{MENIERE'S DISEASE}

Meniere's disease, an inner ear condition, usually manifests itself as vertiginous "attacks" with nausea, accompanied by tinnitus and hearing loss. Following the appearance of these symptoms, which may be severe, remission periods occur ${ }^{22}$. Prosper Meniere first described this disease in $1861 \mathbf{B}^{\mathbf{8} 33}$ and considered the hearing loss as its cardinal symptom ${ }^{32}$. However today, there is confusion in the minds of many, as to the symptoms and pathological changes which should be ascribed to the disease, due mainly to the fluctuation of symptoms. Meniere's disease is thus difficult to diagnose, 7,25,26,32 An important factor in diagnosis appears to be that all symptoms vary simultaneously i.e. they appear to be directly related to one another, ${ }^{32,33}$ but even this is in dispute 2,25 . While some authors consider the symptom triad necessary for diagnosis 6,26 others do not feel it is necessary 27,32 while yet a third group of authors have added the symptom of 'fullness in the ear' to those mentioned by Meniere. ${ }^{24,30}$ Diagnosis is complicated by the fact that while the symptom triad may be present when the disease is fully developed ${ }^{18}$, any one of the symptoms may preceed the others by months or years ${ }^{2}$. The term 'Meniere's disease' has undoubtedly been applied to many other conditions, ${ }^{32}$ and the writer feels that new diagnostic procedures should be invest igated to assist in diagnosis.

It has been hypothesised that the symptoms found in Meniere's disease may be related to increases in edolymphatic pressure. Recruitment and hearing loss are believed to result from hair cell distortion due to pressure increases in the scala media ${ }^{32}$. Feldman 30,26 feels that the symptom of fullness in the ear is the subjective impression of saccule dilation, while vertigo occurs when the pressure in the endolymph has built up to its height. The remaining symptom, tinnitus, has not yet been explained ${ }^{8}$. Originally, endolymphatic hydrops (an accumulation of liquid in the endolymphatic spaces ${ }^{7}$ ) was felt to be an essential finding in Meniere's disease ${ }^{10}$. This condition was found to have produced dilation of the saccule which occupied the whole vestibule and came into contact with the stapes footplate. Dilation of the scala media was also found. However, some authors have had negative findings in this respect ${ }^{32}$. Generally there is agreement that fluctuations in edolymphatic hydrops occur, linked to symptom fluctuation. ${ }^{10,30}$. Many treatments, either medical or surgical, have been developed around the relief of increased endolymphatic pressure 7 , among these are attempts to control the formation and absorption of endolymph $21,31,30$. Due to symptom fluctuations, the success of these treatments is difficult to ascertain ${ }^{7}$, although generally, they have failed to give lasting relief 24 . The writer feels that pressure changes within the endolymph may be detectable in the impedance characteristics of the middel ear, via the oval window.

\section{IMPEDANCE AUDIOMETRY}

Impedance audiomet ry was first introduced by Metz, twenty five years ago. It is widely used in Europe and the United States, as an important part of the battery of special audiometric tests ${ }^{14}$. The techniques are used and designed to diagnose and distinguish between middle ear pathologies 4 . Determination 
of the ear canal volume, under various air pressure conditions, is the basis for all measures with the Electroacoustic Impedance Balancing Bridge ${ }^{\mathbf{2 8}}$.

Sensori-neural pathologies, when tested using impedance techniques, appear as normal ears, providing the middle ear is normal. There has thus far been no real distinction between these, using impedance techniques, other than the detection of recruitment in the more severly impaired ears 12 .

Three basic impedance tests are generally used in order to gain a complete picture of the middle ear function:-

Tympanometry - "The measurement of eardrum compliance" and mobility

"under artificially induced air pressure changes in the ear canal" 16 . The mea. surement of the middle ear pressure is included in the test.

Acoustic Impedance Measurement - the measurement of the amount of resistance to sound waves at the plane of the tympanic membrane ${ }^{5}$.

Acoustic Reflex Measurements - detection of impedance changes as a result of contraction of one or both middle ear muscles ${ }^{5}$. The absence of this reflex may have several pathological causes ${ }^{9.12}$ while Jerger notes that a small percentage of normal ears do not exhibit this reflex ${ }^{12}$.

The acoustic reflex is defined as "that level above the threshold of hearing, at which a sound is just capable of eliciting a reflex cont raction of the stapedius muscle" ${ }^{16}$, this is usually at between $70-100 \mathrm{~dB} \mathrm{SL}{ }^{12}$. The reflex test is considered by Jerger 12 to be the most objective test of recruitment so far constructed.

In interpreting the results of these tests, normative data should be known, however this is not yet available excepting in the case of gross middle ear anomalies $^{13}$. In Metz's study in 1945 wide variation in impedance values were found ${ }^{28}$ and Jerger reports an overlap between normal and disordered ears ${ }^{12}$. There would be great advantages to be gained if impedance techniques could be added to the diagnostic test battery for Meniere's disease to confirm impressions already gained by the clinician ${ }^{12}$. This is especially true in cases of mental retardation or gross physical handicaps where other tests would not be suitable. When considering surgery, which may be unnecessary or dangerous, confirmation of diagnosis is important 21 . Variables such as stress, anxiety, fatigue (all exaggerated in sufferers of Meniere's disease), and intelligence factors could be eliminated due to the nature of impedance tests $8,16,24$. These tests have been successfully used in the diagnosis of psychogenic deaf. ness, retro-cochlear pathologies and sensorineural hearing loss with recruitment $9,12,19,29$ which according to Fowler ${ }^{16}$ is a sign of cochlear pathology and therefore to be expected in Meniere's disease.

In Subjects with Meniere's disease, Jerger 12 found type A tympanograms with normal acoustic impedance. The acoustic reflex was noted to occur at normal intensity levels i.e. $70-100 \mathrm{~dB}$ but at reduced sensation levels, indicating recruitment. However, Zwislocki ${ }^{35}$, Feldman ${ }^{5}$ and Friedman 6 feel that impedance is influenced by the inner ear, notably the compliance of the cochlear windows and the acoustic impedance at the cochlear entrance ${ }^{35}$, which in turn is controlled by conditions existing in the inner ear ${ }^{34}$. Pathology of the inner ear that may in turn effect the middle ear via the cochlear windows 
may show some anomaly in impedance testing as suggested by Macrae ${ }^{19}$. According to histological findings, Meniere's disease would qualify as such a disease.

\section{METHOD}

\section{SUBJECTS}

Ten subjects were obtained by contact with ENT specialists -6 males between the ages of 27 and 68 years with a mean age of 50 years, and 4 females between the ages of 35 and 62 years with a mean of 48 years 3 months. Due to difficulty in obtaining subjects, it was necessary to include subjects in whom presbycusis could have influenced test results.

All subjects were White South Africans from various income groups as noted by their addresses of residence. The subjects were examined by ENT specialists within 10 months of taking part in the study and a diagnosis of unilateral Meniere's disease was made, based on the symptom triad and case history data. Otoscopic examination, no longer than 4 months prior to the study, confirmed that no middle ear pathologies existed.

Control for the experiment was supplied by the unaffected ear of each subject which was expected to show the normal impedance values for that individual.

\section{PROCEDURE}

Subjects were seen individually and took part in the following:

Completion of a questionnaire

Pure tone audiometry (air and bone conduction)

Impedance audiometry (tympanometry, acoust ic impedance test and acoustic reflex measurements)

\section{Questionnaire}

The questionnaire was given to ascertain a possible correlation between the symptoms experienced and the test results. Questions were asked as to which of four symptoms were present, in which ear, with a description of the symptom where appropriate. The date of the last attack was also noted.

\section{Pure Tone Audiometry}

Bilateral tests in the ascending order, for air and bone conduction were carried out, using a Maico MA 24 Audiometer, calibrated to the ISO 1964 reference standard and situated in an acoustically treated booth (IAC Series 1604-Act). Bone conduction was carried out for the speech frequencies and narrow, band masking was used where appropriate, in air and bone conduction.

Impedance Audiometry

The Madsen ZO 70 Electro-acoustic Impedance Balancing Bridge was used to obtain the following three measures bilaterally:

A tympanogram with readings taken for every pressure change of $50 \mathrm{~mm}$ of water. Middle ear pressure was also measured. Acoustic impedance was measured in acoustic ohms and calculated according to the mathematical formula. 
Thresholds for the acoustic reflex were obtained for $1000 \mathrm{~Hz}, 2000 \mathrm{~Hz}, 4000$ $\mathrm{Hz}, 500 \mathrm{~Hz}$, and $250 \mathrm{~Hz}$ in that order, using the ascending method.

Auditory signals were provided by an Amplivox 51 audiometer calibrated to the ISO 1964 standard, the limits of the audiometer being as follows:-

$$
\begin{array}{r}
250 \mathrm{~Hz}-75 \mathrm{~dB} \\
500 \mathrm{~Hz}-85 \mathrm{~dB} \\
1000 \mathrm{~Hz}-95 \mathrm{~dB}
\end{array}
$$

The reflex elicited was recorded for the stimulated ear.

\section{RESULTS AND DISCUSSION}

\section{QUESTIONNAIRE}

The symptoms included in the questionnaire were Meniere's traid plus 'fullness in the ear' which is increasingly being thought of as symptomatic of Meniere's disease $7,24,30,33$. Although each subject had previously experienced all four symptoms, Table I shows that at the time of testing, five felt free of symptoms and five reported symptoms. Of these five subjects, all had tinnitus, four reported hearing losses, one had fullness in the ear and none

\begin{tabular}{|c|c|c|c|c|c|}
\hline \multirow{2}{*}{$\begin{array}{l}\text { SUB- } \\
\text { JECTS }\end{array}$} & \multicolumn{5}{|c|}{ SYMPTOMS EXPERIENCED AT THE TIME OF TESTING } \\
\hline & TINNITUS & $\begin{array}{l}\text { HEARING } \\
\text { LOSS }\end{array}$ & $\begin{array}{l}\text { FULLNESS } \\
\text { IN THE EAR }\end{array}$ & VERTIGO & NONE \\
\hline 1 & $\mathrm{X}$ & $\mathrm{X}$ & & & \\
\hline 2 & $\mathrm{X}$ & $\mathrm{X}$ & & & \\
\hline-3 & & & & & $\mathrm{X}$ \\
\hline 4 & $\mathrm{X}$ & & & & \\
\hline 5 & & & - & & $\mathrm{X}$ \\
\hline 6 & $\mathrm{X}$ & $\mathrm{X}$ & & & \\
\hline 7 & & & & & $\mathrm{X}$ \\
\hline 8 & $\mathrm{X}$ & $\mathrm{X}$ & $\mathrm{X}$ & & \\
\hline 9 & & & & & $\mathrm{X}$ \\
\hline 10 & & & & & $\mathrm{X}$ \\
\hline TOTAL & 5 & 4 & 1 & 0 & 5 \\
\hline
\end{tabular}
experienced vertigo. The time that had elapsed since the last at tack ranged from 1 to 11 months.

TABLE I. Distribution of Subjects according to number and type of symptoms experienced when tested. 
It could be anticipated that not all symptoms would be experienced by each subject as symptoms are known to fluctuate, ${ }^{2,8}$ and only the active stage of the disease is characterised by vertigo ${ }^{26,32}$.

Of the subjects later found to have hearing losses (seven in all), only four reported noticing such a loss. This may be due to compensation for the loss, by the good ear ${ }^{23,32}$ for example in the case of Subjects 5 and 7. Tinnitus may also prove so disturbing that the hearing loss goes unnoticed ${ }^{26}$. Increased endolymphatic pressure cannot be presumed because of the presence of a hearing loss and/or tinnitus as these are reported to become independent of pressure changes in the later stages of the disease $\mathrm{e}^{2,21,33}$.

Only Subject 8 experienced fullness in the ear which Lindsay ${ }^{7}$ and Fick ${ }^{30}$ regard as an indication of increased endolymphatic pressure. It is felt that this Subject could therefore show high acoustic impedance values.

In the earlier stages of the disease, Sataloff ${ }^{26}$ reports the occurrence of unpredictable remissions for a few days or years with an unpredictable number of symptoms remaining, although the later stages of the disease are characterised by the symptom triad 8,26 .

\section{PURE TONE AUDIOMETRY}

Table II shows that 7 Subjects had hearing losses in the affected ear. Bone conduction thresholds confirmed these losses to be sensori-neural.

The only hearing losses seen in the unaffected ears were recorded for Subjects $1,5,6$, and 8 , all over 60 years of age who had falling sensori-neural losses. It is possible that presbycusic hearing losses may have been superimposed on the losses due to Meniere's disease, thus giving the audiograms falling configurations wnich may not otherwise have occurred. Sataloff states that with presbycusic losses, both ears will be affected at the same rate ${ }^{26}$.

Three shapes of audiograms were recorded for the effected ears:-

$$
\begin{aligned}
\text { Flat } & - \text { Subject } 5 \\
\text { Rising } & - \text { Subjects } 2,4 \text { and } 7 \\
\text { Falling } & - \text { Subjects } 1,6 \text { and } 8
\end{aligned}
$$

Controversy exists about expected audiometric configurations in Meniere's disease. The report of the Subcommittee on Equilibrium and Its Management 25 states that, in the early stages, audiograms may show flat or rising configurations. Golding-Wood ${ }^{8}$ feels that diagnosis may not be made unless the configuration is falling, as in the later stages of the disease. He also quotes Wright (1942) and Opheim and Flottorp (1957) who found no typical audiogram for Meniere's disease. 


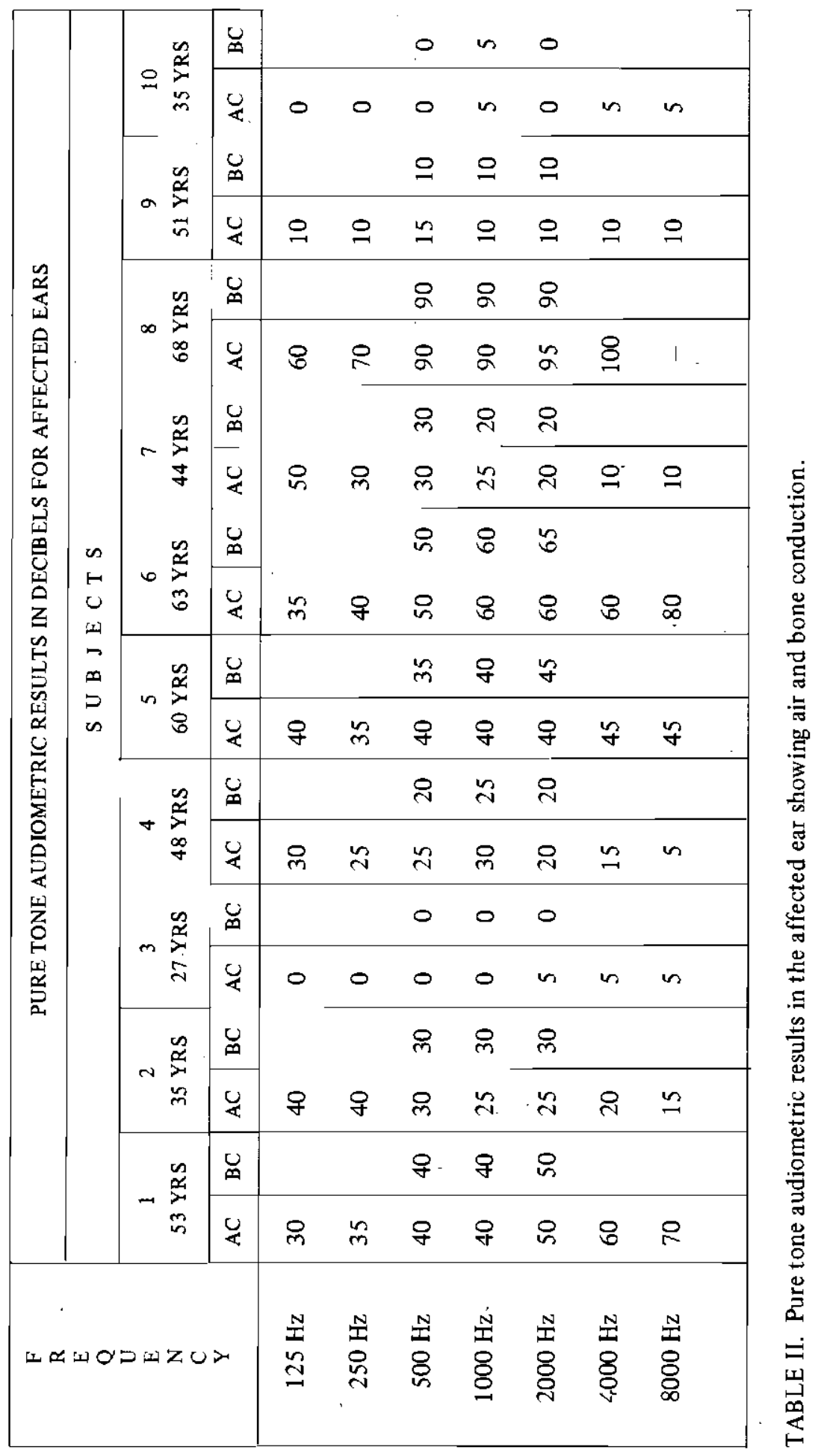


Rising audiograms were seen in Subjects between 35 and 48 years of age where the losses were mild to moderate. It would seem that these Subjects had not reached advanced stages of the disease, as Meniere stated that deafness may become severe or complete in the later stages ${ }^{33}$.

Age appears to correlate with audiometric configurations although the literature does not support this. Caparosa ${ }^{2}$, however, states that the disease most often begins in those over 30 years of age, and it would therefore be expected to reach its advanced stages in the later years of life.

\section{IMPEDANCE AUDIOMETRY}

\section{Tympanometry}

All Subjects presented with bilateral Type A tympanograms with the exception of Subject 8 who had a Type B tympanogram in the affected ear. Tym. panograms were classified according to Jerger's descriptions ${ }^{12}$.

If increased endolymphatic pressure is present and sufficiently great to influence impedance test results, the Subjects should have shown less compliance in the affected ear than expected in normal subjects. However, none of the Subjects with Type A tympanograms reported the feeling of fullness in the ear, which is felt to reflect inner ear pressure increases ${ }^{4,30}$. Subject 8 who experienced fullness in the affected ear showed a Type B tympanogram in this ear, indicating decreased compliance of the tympanic membrane. Both the fullness in the ear and the tympanogram results could indicate inner ear pressure changes influencing the function of the middle ear.

\section{Middle Ear Pressure}

All Subjects, with the exception of Subject 5, had middle ear pressures of $O$ $\mathrm{mm}$ of water bilaterally. Subject 5 had bilateral middle ear pressures of -25 $\mathrm{mm}$ of water. All are within normal limits 12 .

Normal middle ear pressures were to be expected if all Subjects had normal middle ears, due to the pressure equalising function of the Eustachian Tube ${ }^{17}$ Otoscopic examination plus the results of tympanometry support the view that the Subjects were all free of middle ear pathologies. The normal middle ear pressure recorded for Subject 8 strengthens the hypothesis that the Type $B$ tympanogram was the result of interference with the normal movement of the stapes footplate due to inner ear pressure changes.

\section{Acoustic Impedance Values}

Table III shows that acoustic impedance values were between 1045 and 6108 acoustic ohms with a mean value of 2760.7 acoustic ohms in the affected ear. The mean for the unaffected ear was $\mathbf{1 5 1 9 . 1}$ acoustic ohms.

The acoustic impedance values for the affected ears for the Subjects with symptoms were as follows:-

$$
\begin{aligned}
& \text { Subjects 1, } 2 \text { and } 4 \text { - normal } \\
& \text { Subjects } 6 \text { and } 8 \text { - high }
\end{aligned}
$$

In each case, the values recorded for the affected 'ears were higher than those recorded for the other ear. 


\begin{tabular}{|c|c|c|c|c|c|c|c|c|c|c|}
\hline & \multicolumn{10}{|c|}{ BILATERAL ACOUSTIC IMPIEDANCE VALUES IN ACOUSTIC OIIMS } \\
\hline & \multicolumn{10}{|c|}{$S U B J E C T S$} \\
\hline & 1 & 2 & 3 & 4 & $s$ & 6 & 7 & 8 & 9 & 10 \\
\hline $\begin{array}{c}\text { AFFECTED } \\
\text { EAR }\end{array}$ & 1380 & 2360 & 3190 & 2162 & 2856 & 4983 & 1156 & 6108 &.$^{1172}$ & 1680 \\
\hline $\begin{array}{l}\text { UNAFFECTED } \\
\text { EAR }\end{array}$ & 1045 & 1390 & 1380 & 1362 & $12 ! 4$ & 1785 & 1733 & 2520 & $21 \mathrm{~B} 4$ & 1228 \\
\hline
\end{tabular}

TABLE III. Bilateral acoustic impedance values.

The acoustic impedance values for the affected ears of Subjects without symptoms were as follows:-

$$
\begin{gathered}
\text { Subjects 5, 7,9 and } 10 \text { - normal } \\
\text { Subject } 3 \text { - high }
\end{gathered}
$$

Three of these Subjects had higher values in the affected ear than in the unaffected ear.

In Subjects 3, 5, 6 and 8 acoust ic impedance values in the affected ear were more than double that in the unaffected ear. According to Jerger ${ }^{12}$, normal subjects may have acoustic impedance values from 800 to 4200 acoustic ohms, but the majority range from 1000 to 3000 acoust ic ohms, with $10 \%$ overlap between normal and pathological ears. In this study, three Subjects had impedance values above 3000 acoustic ohms in the affected ear. If, as is presumed, the middle ear is normal, these results could be due to increase endolymphatic pressure influencing test results $1,3,10,18$.

The acoustic impedance value of 3190 acoustic ohms for the affected ear of Subject 3 is close to the normal limits and his other test results were all normal. However, this acoustic impedance value is more than double that for the unaffected ear, a phenomenon also noted for Subjects 5,6 and 8 . Je rger 12 feels this great difference in impedance values for the ears of one individual could be an indication of pathology. However, this comparison can be made only if one ear is normal ${ }^{12}$. Inter-subject comparison is favoured in this study as normative data is insufficient for intra-subject comparison to be reliable 26

It is possible that individuals have different physical tolerances to increased endolymphatic pressure and, as a result, there is no single numerical value in acoustic ohms beyond which all subjects develop symptoms. A percentage increase over the individual's normal values may be the critical factor.

All five Subjects who experienced symptoms, plus three of those who did not, had higher acoustic impedance values in the affected ear, making a total of $80 \%$ of the Subjects.

The impedance value recorded for Subject 8 may have been sufficiently high to influence the movement of the tympanic membrane hence the Type B tympanogram, unlike Subjects 3 and 6 whose impedance values were lower and whose tympanograms were normal. Subject 8 also experienced fullness in the ear thought to be the subjective impression of increased inner ear pressure ${ }^{4}$. 
Endolymphatic pressure may be sufficiently increased to influence the results of acoustic impedance tests but not sufficient to produce the symptom of fullness in the ear, hence the result for Subjects 3 and 6 who had no fullness but had high impedance values.

Arnvig ${ }^{10}$ stated that symptoms appear to be able to preceed the development of increased endolymphatic pressure. This view could explain the results of Subjects 1, 2 and 4 who had symptoms but normal acoustic impedance values in the affected ear. It can be seen that no clear link has been established between symptoms and endolymphatic pressure increases ${ }^{8}$.

\begin{tabular}{|c|c|c|c|c|c|c|c|c|c|c|}
\hline \multirow{4}{*}{$\begin{array}{l}\mathrm{S} \\
\mathrm{U} \\
\mathrm{B} \\
\mathrm{J} \\
\mathrm{E} \\
\mathrm{C} \\
\mathrm{T} \\
\mathrm{S}\end{array}$} & \multicolumn{10}{|c|}{$\begin{array}{c}\text { DECIBEL-VALUES OF ACOUSTIC REF LEXES AT SENSATION } \\
\text { 1.FVELS BFLOW } 60 \mathrm{~dB} \text { IN AFFECTED EAR }\end{array}$} \\
\hline & \multicolumn{10}{|c|}{ FREQUENCIES TESTFD } \\
\hline & \multicolumn{2}{|c|}{$250 \mathrm{~Hz}$} & \multicolumn{2}{|c|}{$500 \mathrm{~Hz}$} & \multicolumn{2}{|c|}{$1000 \mathrm{~Hz}$} & \multicolumn{2}{|c|}{$2000 \mathrm{~Hz}$} & \multicolumn{2}{|c|}{$4000 \mathrm{~Hz}$} \\
\hline & $\mathrm{HL}$ & SL & $\mathrm{HL}$ & SI. & HI. & SL & $\mathrm{HL}$ & $\mathrm{SL}$ & $\mathrm{HL}$ & SL \\
\hline 1 & 75 & 40 & 85 & 45 & 95 & 55 & \multirow[t]{2}{*}{90} & \multirow[t]{2}{*}{40} & \multirow[t]{2}{*}{90} & 30 \\
\hline 2 & 75 & 35 & 80 & \multirow[t]{2}{*}{50} & 75 & 55 & & & & \\
\hline 3 & & & & & & \multirow[b]{2}{*}{55} & & & & \\
\hline 4 & 70 & 45 & 80. & 55 & 85 & & & & & \\
\hline 5 & 75 & 40 & 85 & 45 & 95 & 55 & 95 & 55 & 95 & 50 \\
\hline 6 & 75 & 35 & 85 & 35 & 95 & 35 & 95 & 35 & 95 & 35 \\
\hline 7 & 75 & 45 & 85 & 55 & & & & & & \\
\hline 8 & & & & & & & & & & \\
\hline 9 & & & & & & & & & & \\
\hline 10 & & & & & & & & & & \\
\hline
\end{tabular}

TABLE IV. Acoustic reflex thresholds at sensation levels below $60 \mathrm{DB}$ in affected ears.
HL $=$ Hearing Level
SL $=$ Sensation Level

Acoustic Reflex Threshold

Table IV shows the number and frequencies of acoustic reflexes for all Subjects, elicited below $60 \mathrm{~dB}$ SL in the affected ear. The largest number of such reflexes was seen for $250 \mathrm{~Hz}$ with the numbers decreasing as the frequency in. creased. 
Only 4 instances of reflexes at reduced sensation levels were recorded in the unaffected ears. They were: -

Subject $1-4000 \mathrm{~Hz}$ at a sensation level of $50 \mathrm{~dB}$

Subject $6-4000 \mathrm{~Hz}$ at a sensation level of $40 \mathrm{~dB}$

Subject $8-250 \mathrm{~Hz}$ at a sensation level of $55 \mathrm{~dB}$

$1000 \mathrm{~Hz}$ at a sensation level of $50 \mathrm{~dB}$

All these frequencies were felt to be influenced by presbycusis. Subjects 3, 9 and 10 showed no reflexes below $60 \mathrm{~dB}$ SL while Subject 8 did not demonstrate any reflexes in the affected ear, and only two reflexes (at below $60 \mathrm{~dB}$ $\mathrm{SL}$ ) in the unaffected ear. In ears with normal hearing, no reflexes were elicited at below $60 \mathrm{~dB}$ SL.

In determining the reflex thresholds, Jerger's definition of the threshold was used - the lowest level of the signal that can produce a deflection of the balance meter needle that can be observed ${ }^{12}$. The presence of the reflex shows an intact reflex arc and the good working order of the middle ear 11,4. A reflex elicited at less than $60 \mathrm{~dB}$ SL is considered by Jerger ${ }^{12}$ to be an indication of recruitment. Fowler ${ }^{8}$, described recruitment as a site of lesion in. dicator, demonstrating cochlear pathology, and recruitment would thus be predicted in ears showing sensori-neural hearing loss. The results of this study support this prediction. Results also corroborated evidence of other studies $12,13,35$ that, as hearing becomes poorer, so the sensation level needed to elicit a reflex decreases.

The lowest recorded sensation level at which a reflex was elicited in this study was $30 \mathrm{~dB}$. Jerger ${ }^{13}$ noted $25 \mathrm{~dB}$ as the lowest level beyond which a reflex will not occur, but Ewertsen et $\mathbf{a l}^{16}$ found reflexes at $10 \mathrm{~dB}$ SL.

Of the three reflexes recorded for Subject 8 , all were in the unaffected ear and 2 showed recruitment, possibly due to presbycusis. The lack of reflex response in the other frequencies could be due to the fact that he has only a relatively mild hearing loss in those frequencies and therefore does not experience recruitment. Feldman ${ }^{4}$ feels that a hearing loss should cause a sufficient decrease in loudness to eliminate the acoustic reflex (providing there is no recruitment). Hearing thresholds in the affected ear of Subject 8 were such that a reflex could be expected only at $250 \mathrm{~Hz}$, due to the limits of the audiometer. No recruitment was shown in Subjects with normal hearing in the affected ear. in agreement with Fowler ${ }^{16}$, Williams ${ }^{32}$ and Schuknecht ${ }^{27}$ who associate recruitment with cochlear pathology. Those Subjects with no recruitment were also free of other symptoms of Meniere's disease and could be considered to have complete symptom remissions.

In this study, higher thresholds for the acoustic reflex may have been obtained by using the ascending method of tone presentation than if the descending method had been used. Test results seem to depend on the stage of development of the disease which Sataloff 26 feels, dictates whether a complete or partial remission occurs. Any diagnosis of Meniere's disease must be able to confirm the presence of recruitment which is one of the main features of the disease. This is clearly possible with impedance techniques. 


\section{CONCLUSION}

The results of the impedance technique employed in this study indicates one abnormal tympanogram and acoustic imped ance values higher in $80 \%$ of the affected ears when compared to the unaffected ears. Four of these higher values were double the acoustic impedance in the unaffected ear of the same Subject, and three of the values were above normal limits. Recruitment was shown in all ears with hearing losses. The difference in acoustic impedance values between an individual's ears may be more important than the values per se.

Further studies using individuals who each experience several of the symptoms of Meniere's disease at the time of testing may result in more reliable findings.

The findings of this study are limited due to the inclusion of Subjects who were in the age group where presbycusis can be expected and generalisations to the population of Meniere's disease sufferers cannot be made, due to the small number of subjects used.

Some attempts should be made to correlate the acoustic impedance values with results from other tests, used in the diagnosis of Meniere's disease. Lamb and Norris ${ }^{16}$ feel that if impedance test results agreed with the ABLB Test, which according to Fowler ${ }^{8}$, indicates cochlear pathology, impedance techniques would be shown to have validity as a test of cochlear function.

Impedance techniques could, after further research, have a place in a test battery for the diagnosis of Meniere's disease, where these may find additional application in recording the gradual pressure increase in the edolymphatic spaces. In this way, attacks may be predicted and appropriate preventative. treatment given. The evaluation of treatments for the relief of increased endolymphatic pressure may be enhanced by the use of impedance techniques.

\section{REFERENCES}

1. Altmann, F. \& Kornfeld, M. (1965): Histological Studies of Meniere's Disease. Ann. of Otol, Rhinol, \& Laryngol, 74, 915.

2. Caparosa, R.J., (1963): Medical Treatment for Meniere's Disease. The Laryngoscope, 73, 666.

3. Day, K.M., (1963): Twenty-five Years Experience with Meniere's Disease. The Laryngoscope, 73, 693.

4. Feldman, A.S., (1963): Impedance Measurements at the Eardrum as an Aid to Diagnosis. JSHR, 6, 315

5. Feldman, A.S., (1971): Impedance Measurement and the Middle Ear Part 1. Maico Audiological Library Series, 9, Report 7.

6. Friedman, I., (1974): Pathology of the Ear, Blackwell Scientific Publication, London.

7. Godlowski, Z., (1972): Hyperosmosis of Endolymph as Primary Pathogenic Mechanism of Meniere's Dísease, and It Clinical Management. Acta Oto Laryngologica, Supplement 229.

8. Golding-Wood, P.H. (1960): Meniere's Disease and Its Pathological Mechanism. Laryngol \& Otol., 74, 803. 
9. Grason-Stadler, (1973): Instruction Manual for Users of the GrasonStadler Model 1720 Otoadmittance Meter U.S.A.

10. Hallpike, C.S. \& Cairns, H. (1938): Observations on the Pathology of Meniere's Syndrome. Laryngol \& Otol., 53, 625.

11. Jepsen, O., (1963): Middle Ear Muscle Reflexes in Man. In Modern Developments in Audiology. (Ed.) Jerger, J., Academic Press Inc. Ltd., London.

12. Jerger, J., (1970): Clinical Experiences with Impedance A udiometry. Arch. of Otolaryngology, 92, 311 .

13. Jerger, J., Jerger, S.\& Mauldin, L., (1972): Studies in Impedance Audiometry, Normal and Sensorineural Ears. Arch. of Otolaryngology, 96, 513.

14. Johnson, E.W., (1973): Clinical Application of Special Hearing Tests. Arch. of Otolaryngology, 97, 92.

15. Kohut, R.I. \& Lindsay, J.R., (1972): Pathologic Changes in Idiopathic Labyrinthine Hydrops, Correlations with Previous Findings. Acta Oto Laryngologica, 73, 402.

16. Lamb, L.E. \& Norris, T.W., (1969): Acoust ic 1mpedance Measurements. In Audiometry for the Retarded with Implications for the Difficult to Test. (Ed.) Fulton and Lloyd, The Williams \& Wilkins Co., Baltimore.

17. Lamb, L.E., (1971): Impedance Measurement and the Middle Ear Part 11I. Maico Audiological Library Series, 9, Report 9.

18. Lindsay, J.R., Koluut, R.1. \& Sciarra, P.A., (1967): Meniere's Disease: Pathology and Manifestations. Ann.of Otol, Rhinol, \& Laryngol., 76, 5

19. Macrae, J.H., (1973): Acoustic Neuroma and the Acoust ic lmpedance of the Ear. JSHD, 38, 345.

20. Madsen Electronics (1974): Instruction Manual for Madsen Model ZO 70 Electro-Acoustic Impedance Bridge. U.S.A.

21. Mawson, S.R., (1963): Diseases of the Ear. Edward Arnold Ltd., London.

22. McCabe, B.F., Wolsk, D. \& Arbor, A., (1961): Experimental lnner Ear Pressure Changes - Functional Effects. Ann of Otol Rhinol, \& Laryngol., 70, 541 .

23. Noach, M., (1973): Lectures in Audiology I, University of the Witwatersrand. Johannesburg.

24. Pulec, J.L., (1972): Symposium on Meniere's Disease - Meniere's disease: Results of a two and one-half year Study of Etiology, Natural History and Results of Treatment. The Laryngoscope, 82, 1703.

25. Report of the Subcommittee on Equilibrium and lts Management Committce on Hearing and Equilibrium, (1972): Meniere's Disease: Criteria for Diagnosis and Evaluation of Therapy, for Reporting. Transactions of American Academy of Opthalmology and Otolaryngology. 76,1462 .

26. Sataloff, J., (1966): Hearing Loss. J.B. Lippincott Co., Philadelphia \& Toronto.

27. Scluknecht, H.F., (1963): Symposium: Meniere's Disease. Meniere`s Disease: A correlation of Symptomatology and Pathology. The Laryngoscope, 73,651. 
28. Terkildsen, K.\& Scott-Nielsen, S., (1960): An Electroacoustic Measuring Bridge for Clinical Use. Arch. of Otolaryngol, 72, 339.

29. Thomsen, K.A., (1955): Employment of Impedance Measurements in Otologic and Otoneurologic Diagnosis (Review). Acta Oto Laryngologica, $45,159$.

30. Van N. Fick, I.A., (1966): Meniere's Disease: Aetiology and a New Surgical Approch: Sacculotomy (Decompression of the Labyrinth). Laryngol \& Otol, 80, 288.

31. Weiss, A.D., (1966): Calorization in Relation to Otoneurologic Diagnosis. In The Vestibular Syst em and Its Diseases. (Ed.) Wolfson, J.R., Oxford University Press, London.

32. Williams, H.L., (1952): Meniere's Disease. Charles C. Thomas, Illinois, U.S.A.

33. Wilson, T.G., (1965): Symposium: Management of Meniere's Disease Historical Aspects of Meniere's Disease. The Laryngoscope, 75, 1491.

34. Zwislocki, J., (1961): Acoust ic Measurement of the Middle Ear Function. Ann. of Otol. Rhinol, \& Laryngol, 70, 599.

35. Zwislocki, J., (1963): An A coustic Method for Clinical Examination of the Ear. JSHR, 6, 303

\section{Indispensable Books for Teachers \\ of children having language learning problems DEVELOPMENTAL SENTENCE ANALYSIS}

by Professor Laura Lee (Northwestern University) with a chapter by

Roy A Koenigsknecht

This is a Grammatical Assessment Procedure for Speech and Language

Clinicians.

Price R12.60 (R12.35 by post)

\section{INTERACTIVE LANGUAGE DEVELOPMENT TEACHING}

by Professor Laura Lee, Roy A Koenigsknecht, S Mulhern The Clinical Presentation of Grammatical Structure.

Price R13.70 (R14.05 by post)

$$
\begin{gathered}
\text { 34 Bertha Street / Berthastraat } 34 \\
\text { BRAAMFONTEIN 2017 } \\
\text { P.O. Box 31361/ Posbus 31361 } \\
\text { Telephone / Telefoon 72-8541 }
\end{gathered}
$$

